\title{
Molecular Harvesting of Proteins with Electroporation In Vivo Facilitates the Profiling of Spatial Differential Protein Expression in Tumors
}

Edward Vitkin

IDC Herzliya: Reichman University

Amrita Singh

Tel Aviv University

Julia Wise

Tel Aviv University

Shay Ben-Elazar

IDC Herzliya: Reichman University

Zohar Yakhini

IDC Herzliya: Reichman University

Alexander Golberg ( $\square$ agolberg@gmail.com )

Tel Aviv University https://orcid.org/0000-0001-8782-8879

\section{Research Article}

Keywords: 4T1, biopsy, breast tumor, electroporation, e-biopsy, heterogeneity, personalized medicine, proteomics, spatial differential protein expression

Posted Date: February 1st, 2022

DOI: https://doi.org/10.21203/rs.3.rs-1242718/v1

License: (c) (i) This work is licensed under a Creative Commons Attribution 4.0 International License. Read Full License 


\section{Abstract}

Background. Excision tissue biopsy, while central to cancer treatment and precision medicine, presents risks to the patient and does not provide a sufficiently broad and faithful representation of the heterogeneity of sampled solid tumors.

Methods. Here we introduce e-biopsy - a novel concept for molecular profiling of solid tumors using molecular extraction with electroporation. As e-biopsy provides access to the molecular composition of a solid tumor, it potentially facilitates tumor diagnostics without tissue resection. Furthermore, thanks to its less invasive characteristics, e-biopsy enables probing the solid tumor multiple times in several distinct locations in the same procedure, thereby enabling the spatial profiling of tumor molecular heterogeneity.

Results. We demonstrate e-biopsy in vivo, using the 4T1 breast cancer model in mice to assess its performance, as well as the inferred spatial differential protein expression. In particular, we show that proteomic profiles obtained via e-biopsy in vivo distinguish the tumors from healthy tissue and reflect spatial tumor differential protein expression.

Conclusions. E-biopsy provides a completely new molecular cartography modality for solid tumors, providing information that potentially enables more sensitive detection, at lesser risk, as well as more precise personalized medicine.

\section{Background}

Based on molecular profiles of tumors and other tissues, personalized medicine aims to optimize medical care and preventative measures on an individual patient basis. In cancer therapy and care, a clear potential advantage has been demonstrated to the personalized approach as compared to traditional therapies ${ }^{1-3}$. Accurate diagnosis is a critical component of personalized medicine. An important component of molecular diagnostics in patient samples, including tumors, is the profiling of DNA, RNA, proteins, glycans or metabolites, to identify molecular biomarkers that are predictive of tumor type ${ }^{4-7}$ and of potential patient response ${ }^{8,9}$. To enable tumor profiling, current methods use tissue biopsy, which involves the physical resection of a small tissue sample. This procedure leads to localized tissue injury, bleeding, inflammation, neural damage, and stress ${ }^{10,11}$, the effect of which is not well understood ${ }^{12}$. Moreover, standard tissue biopsy could increase the potential for tumor growth and metastasis ${ }^{12-14}$. In addition, because of the negative effects, only a few biopsies can be performed at a time, limiting the scope of the spatial mapping of the sampled site, and leading to misdiagnosis if the tumor is missed. Furthermore, some authors even concluded that due to solid tumor heterogeneity, information from a single biopsy is not sufficient for guiding treatment decisions ${ }^{15,16}$.

Indeed, recent literature identified the absence of efficient technologies for characterizing tumor molecular heterogeneity ${ }^{17}$ as a major limitation of the personalized medicine approach in cancer ${ }^{18}$. Significant genomic evolution often occurs during cancer progression, creating variability within primary tumors as well as between the primary tumors and their metastases ${ }^{16,19-21}$. Recent studies have shown that while a positive result (both successful biopsy and a decisive detection of markers) appears to reliably indicate the presence of the high-risk disease ${ }^{15}$, a negative result does not reliably rule out the presence of high-risk clones ${ }^{22}$. This is partly because a harvested tissue sample may not capture the most aggressive clone of a given tumor or tumor site ${ }^{15,23-25}$. Despite the significant improvement in molecular characterization technologies in recent decades, thanks to the introduction of new high-resolution sequencing and bioinformatics methods, these technologies remain limited by tissue sampling methods ${ }^{16,26}$. Thus, tissue sampling constitutes a critical limitation of personalized medicine ${ }^{15,16,27}$. New approaches to probing and profiling several regions in the tumor at the molecular level, termed molecular cartography, are expected to be useful in this context ${ }^{28,29}$.

To address these issues, and to extend the state-of-the-art of technologies that will potentially enable precision diagnosis and therapy, we developed a novel approach to molecular tissue sampling using electroporation ${ }^{30}$. Electroporation-based technologies have been successfully used to non-thermally irreversibly or reversibly change permeabilization of the cell membrane in vivo, enabling a wide set of applications ranging from tumor ablation to targeted delivery of molecules ${ }^{30}$. We and others previously developed protocols for targeted delivery of electric field to tissues to induce focused electroporation at predetermined regions in organs ${ }^{31-36}$. More recently, we showed that electroporation technologies selectively extract proteins and ash from biomass ${ }^{37-39}$. Although electroporation has been used to deliver molecules to tissues and to ablate multiple tumors and metastatic sites, to the best of our knowledge it has not so far been proposed for extracting molecules for tissue molecular profiling, including tumors in vivo.

The goal of this work is to test molecular harvesting by electroporation (e-biopsy) in vivo and to assess the spatial differential expression at the proteomic level, observable through this novel sampling method. We also compare the proteomic molecular profiles obtained through e-biopsy with state-of-the-art solid tissue lysis buffer extraction. In particular, we show that proteomic profiles obtained by e-biopsy from 4 T1 mice tumors in vivo are tissue specific, consistent, reflect tumor protein expression heterogeneity, and align with proteomic profiles obtained using standard lysis buffers from excised tissue samples. 
Our approach to solid tissue characterization, as described herein, differs substantially from needle or other excision biopsy approaches, which require tissue resection, as well as from liquid biopsy. The latter only measures an average biomarkers profile of the entire organism, and cannot provide precise spatial sub-clonal information. It is also, obviously, limited to the molecular content accessible in the patient's circulation system. E-biopsy, when used in combination with in situ electrodes ${ }^{40-42}$, potentially expands the opportunity for capturing spatial clonal variations. Moreover, due to its minimally invasive nature, e-biopsy potentially facilitates multiple sampling/probing, and thereby higher-resolution spatial molecular cartography of tissues at the macroscale. E-biopsy can thus enable a new type of diagnostic approach for spatial molecular tumor mapping in vivo that is not currently possible.

\section{Results}

\section{E-biopsy for molecular harvesting in vivo}

The e-biopsy method for molecular harvesting in vivo from solid tumors, using electroporation for cell membrane permeabilization, described for the first time in this work, is shown in Fig. 1a. First, the needles are inserted into the solid tissue. Second, the specific series of high-voltage pulsed electric fields (PEF) are applied to permeabilize the cell membrane with electroporation. Third, a vacuum is applied on the same needle through which the PEF pulses are delivered, to pump the released cellular content into the needle and the syringe. Next, the tissue extract is discharged from the syringe to the external buffer, and subjected to standard protocols for molecular analysis, including purification, separation, identification, and quantification. E-biopsy can be repeated in multiple positions in the same area or other areas of the tissue sample. In our study (Fig. 1b), 4T1 tumors (Fig. S1) were sampled 6 times each: 2 times at their centers, 2 times at their peripheries, and 2 times midway between the center and the periphery. Additional sampling was done in the normal breast of the same animal. All animals survived the procedure, and no abnormal responses were observed.

\section{E-biopsy proteomics distinguishes 4T1 tumor samples from healthy breast tissue}

We first consider e-biopsy extracted proteomic profiles in the context of distinguishing between 4T1 tumor and healthy murine breast tissue, regardless of sampling site. Differential analysis of protein expression (paired two-sided t-test with $n=5$, the two replicates from each location were averaged) was performed for three pairs of e-biopsy extracts: 4T1 tumor center vs healthy breast, 4T1 tumor periphery vs healthy breast, and $4 \mathrm{~T} 1$ tumor middle vs healthy breast. We found 13 proteins harvested by e-biopsy (Table 1) strongly overexpressed ( $\mathrm{p}$-value < 0.01 , Methods) in all sampled locations in the tumor vs normal breast (no underexpressed proteins were identified under the same criteria). An intersection of this size has a p-value $<1.5 \mathrm{e}-06$. These 13 proteins therefore represent an FDR of $3.5 \mathrm{e}-04$ (Methods). Moreover, releasing the p-value cutoff to 0.05 results in a set of 242 (238 overexpressed and 4 under-expressed) differentially expressed proteins, corresponding to FDR of $2.3 e-03$. In further analysis we call these 242 proteins - potential 4T1 biomarkers. 
Table 1

List of proteins extracted with e-biopsy that differentiate 4T1 tumor from healthy breast tissue

samples for all tumor sampling locations. This is a list of genes that are overexpressed in all 3 tumor locations together (Center/Midway/Peripheral; with both tumor location replicas averaged

into a single value) compared to healthy breast samples (paired t-test $p$-value $<0.01$ at each location). A two-sided, paired t-test was applied to each of the 4,519 known proteins sampled from

5 mice via e-biopsy. No underexpressed proteins were identified using the same criterion, namely $\mathrm{p}<0.01$ in all three comparisons.

\begin{tabular}{|lllllll|}
\hline Genes & \multicolumn{2}{l}{ Peripheral $>$ Healthy Breast } & \multicolumn{2}{l}{ Middle $>$ Healthy Breast } & \multicolumn{2}{l}{ Center $>$ Healthy Breast } \\
\cline { 2 - 7 } & p-value & t-stats & p-value & t-stats & p-value & t-stats \\
\hline Vim & $8.0 \mathrm{E}-03$ & 4.9 & $1.7 \mathrm{E}-03$ & 7.5 & $1.4 \mathrm{E}-03$ & 7.9 \\
\hline Hnrnpa2b1 & $5.6 \mathrm{E}-04$ & 10.0 & $5.7 \mathrm{E}-04$ & 9.9 & $4.7 \mathrm{E}-04$ & 10.5 \\
\hline Pabpc1 & $5.9 \mathrm{E}-03$ & 5.3 & $8.6 \mathrm{E}-03$ & 4.8 & $3.2 \mathrm{E}-03$ & 6.3 \\
\hline Nucb1 & $7.4 \mathrm{E}-03$ & 5.0 & $3.4 \mathrm{E}-03$ & 6.2 & $2.5 \mathrm{E}-03$ & 6.7 \\
\hline Serpinh1 & $3.8 \mathrm{E}-03$ & 6.0 & $8.6 \mathrm{E}-03$ & 4.8 & $7.8 \mathrm{E}-04$ & 9.2 \\
\hline Hnrnpa1 & $2.9 \mathrm{E}-03$ & 6.5 & $1.8 \mathrm{E}-03$ & 7.3 & $9.4 \mathrm{E}-03$ & 4.7 \\
\hline Slc25a24 & $3.2 \mathrm{E}-03$ & 6.4 & $1.3 \mathrm{E}-03$ & 8.1 & $2.4 \mathrm{E}-03$ & 6.8 \\
\hline Plin3 & $9.9 \mathrm{E}-03$ & 4.6 & $4.5 \mathrm{E}-03$ & 5.8 & $9.7 \mathrm{E}-03$ & 4.6 \\
\hline Hmgb1 & $3.7 \mathrm{E}-04$ & 11.1 & $6.4 \mathrm{E}-03$ & 5.2 & $3.7 \mathrm{E}-03$ & 6.1 \\
\hline Rcn1 & $3.8 \mathrm{E}-03$ & 6.0 & $1.3 \mathrm{E}-03$ & 8.0 & $1.3 \mathrm{E}-03$ & 8.0 \\
\hline Cnpy2 & $3.8 \mathrm{E}-03$ & 6.0 & $9.4 \mathrm{E}-04$ & 8.8 & $4.4 \mathrm{E}-03$ & 5.8 \\
\hline Mat2b & $1.5 \mathrm{E}-03$ & 7.7 & $3.0 \mathrm{E}-03$ & 11.7 & $2.5 \mathrm{E}-03$ & 6.8 \\
\hline Bax & $6.3 \mathrm{E}-03$ & 5.2 & $1.2 \mathrm{E}-04$ & 14.9 & $2.6 \mathrm{E}-03$ & 6.7 \\
\hline
\end{tabular}

The distribution of the observed differential expression scores, computed from comparing protein measurements in the healthy breast versus the different 4T1 tumor locations, is statistically significant, manifesting an overabundance of differentially expressed proteins. As shown in the overabundance plots (Fig. 2), there are more differentially expressed proteins observed in our data than expected under a random null model ${ }^{43}$.

Gene Ontology (GO) analysis of 4,519 e-biopsy-extracted proteins was used to further examine the differential expression between control (healthy breast) and three 4T1 tumor locations in terms of cellular processes, functions, and components. Here we present the most significant (p-value < 1E-06 at all locations simultaneously) differentially regulated processes, functions, and components (Tables 2-7) and discuss several interesting observations. All identified processes, functions, and components that are simultaneously enriched in all positions with p-value $<1 \mathrm{E}-$ 06 are presented online in https://github.com/GolbergLab/eBiopsy4T1.

Notably, the analysis of the GO terms revealed several significant (p-value < 1E-06 in all locations) down-regulated cellular processes in 4T1 tumor (Table 2). Among them there are many immunoglobulin-related processes, which is consistent with earlier reports ${ }^{44}$, who found that intratumoral injection of allogeneic IgG combined with other factors induced nearly complete eradication of lung metastases from 4T1. The downregulation of various peptidase inhibitors-related cellular functions (Table 3) in 4T1 is also consistent with previous works ${ }^{45}$. Moreover, the tumor's extracellular component in all three locations was downregulated compared to the healthy breast (Table 4), which is expected in aggressive and invasive tumors such as $4 \mathrm{~T}^{46}$. Furthermore, we found that many biosynthesis-related cellular processes are up-regulated in $4 \mathrm{~T} 1$ (Table 5), which is consistent with the tumor's need for enhanced replication rates ${ }^{47}$. These findings are also supported by many upregulated cellular functions (Table 6) and cellular components (Table 7).

These data show that in vivo e-biopsy extraction of proteins yields statistically significant and biologically different profiles when comparing various locations in $4 \mathrm{~T} 1$ tumors to healthy breast tissue in mice. 
Table 2

GO Process terms significantly underexpressed in all 4T1 tumor locations vs healthy breast.

Two-sided, paired t-test p-value $<1 \mathrm{E}-06$ for all 3 tumor locations simultaneously. Highlighted cells indicate maximal p-value amongst the three different locations.

\begin{tabular}{|llll|}
\hline Description & Center & Middle & Peripheral \\
\hline protein activation cascade & p-value & p-value & p-value \\
\hline complement activation & $3.22 \mathrm{E}-18$ & $1.73 \mathrm{E}-20$ & $5.40 \mathrm{E}-22$ \\
\hline humoral immune response & $8.94 \mathrm{E}-16$ & $8.47 \mathrm{E}-19$ & $3.35 \mathrm{E}-20$ \\
\hline complement activation, classical pathway & $4.67 \mathrm{E}-14$ & $1.09 \mathrm{E}-14$ & $1.41 \mathrm{E}-16$ \\
\hline immune response & $7.83 \mathrm{E}-14$ & $3.00 \mathrm{E}-15$ & $3.27 \mathrm{E}-17$ \\
\hline phagocytosis, recognition & $1.25 \mathrm{E}-12$ & $6.54 \mathrm{E}-14$ & $2.51 \mathrm{E}-13$ \\
\hline response to bacterium & $2.01 \mathrm{E}-11$ & $3.20 \mathrm{E}-11$ & $6.07 \mathrm{E}-13$ \\
\hline immunoglobulin production & $1.48 \mathrm{E}-13$ & $5.56 \mathrm{E}-11$ & $6.66 \mathrm{E}-13$ \\
\hline production of molecular mediator of immune response & $4.21 \mathrm{E}-11$ & $3.17 \mathrm{E}-10$ & $1.16 \mathrm{E}-11$ \\
\hline blood coagulation & $9.27 \mathrm{E}-10$ & $3.91 \mathrm{E}-10$ & $4.44 \mathrm{E}-10$ \\
\hline Coagulation & $9.27 \mathrm{E}-10$ & $3.91 \mathrm{E}-10$ & $4.44 \mathrm{E}-10$ \\
\hline defense response to bacterium & $1.25 \mathrm{E}-12$ & $1.15 \mathrm{E}-09$ & $1.55 \mathrm{E}-11$ \\
\hline Hemostasis & $5.76 \mathrm{E}-09$ & $2.53 \mathrm{E}-09$ & $1.37 \mathrm{E}-09$ \\
\hline immune system process & $1.02 \mathrm{E}-08$ & $1.35 \mathrm{E}-08$ & $1.92 \mathrm{E}-09$ \\
\hline defense response & $2.11 \mathrm{E}-08$ & $1.25 \mathrm{E}-08$ & $2.28 \mathrm{E}-10$ \\
\hline B cell receptor signaling pathway & $4.98 \mathrm{E}-08$ & $3.14 \mathrm{E}-09$ & $3.93 \mathrm{E}-09$ \\
\hline phagocytosis, engulfment & $1.60 \mathrm{E}-07$ & $1.60 \mathrm{E}-07$ & $1.50 \mathrm{E}-08$ \\
\hline activation of immune response & $1.71 \mathrm{E}-07$ & $4.62 \mathrm{E}-07$ & $5.06 \mathrm{E}-09$ \\
\hline
\end{tabular}

Table 3

GO Function terms significantly underexpressed in all 4T1 tumor locations. Twosided, paired t-test p-value $<1 \mathrm{E}-06$ for all 3 tumor locations simultaneously. Highlighted cells indicate maximal p-value between 3 areas.

\begin{tabular}{|llll|}
\hline Description & $\begin{array}{l}\text { Center } \\
\text { p-value }\end{array}$ & $\begin{array}{l}\text { Middle } \\
\text { p-value }\end{array}$ & Peripheral \\
& $1.25 \mathrm{E}-09$ & $1.51 \mathrm{E}-08$ & $2.24 \mathrm{E}-09$ \\
\hline endopeptidase inhibitor activity & $2.23 \mathrm{E}-09$ & $2.21 \mathrm{E}-08$ & $4.50 \mathrm{E}-09$ \\
\hline peptidase inhibitor activity & $3.93 \mathrm{E}-09$ & $6.20 \mathrm{E}-08$ & $2.27 \mathrm{E}-08$ \\
\hline serine-type endopeptidase inhibitor activity & $3.40 \mathrm{E}-08$ & $1.24 \mathrm{E}-07$ & $8.67 \mathrm{E}-08$ \\
\hline endopeptidase regulator activity & $1.82 \mathrm{E}-07$ & $2.71 \mathrm{E}-07$ & $5.09 \mathrm{E}-07$ \\
\hline peptidase regulator activity & & & \\
\hline
\end{tabular}


Table 4

GO Component terms significantly underexpressed in all 4T1 tumor locations.

Two-sided, paired t-test $\mathrm{p}$-value $<1 \mathrm{E}-06$ for all 3 tumor locations simultaneously. Highlighted cells indicate maximal p-value between 3 areas.

\begin{tabular}{|llll|}
\hline Description & $\begin{array}{l}\text { Center } \\
\text { p-value }\end{array}$ & $\begin{array}{l}\text { Middle } \\
\text { p-value }\end{array}$ & $\begin{array}{l}\text { Peripheral } \\
\text { p-value }\end{array}$ \\
\hline extracellular region part & $5.62 \mathrm{E}-21$ & $9.83 \mathrm{E}-27$ & $7.23 \mathrm{E}-28$ \\
\hline extracellular space & $3.25 \mathrm{E}-20$ & $3.63 \mathrm{E}-25$ & $1.09 \mathrm{E}-22$ \\
\hline extracellular region & $3.28 \mathrm{E}-15$ & $1.66 \mathrm{E}-17$ & $4.03 \mathrm{E}-18$ \\
\hline immunoglobulin complex & $4.51 \mathrm{E}-12$ & $6.80 \mathrm{E}-13$ & $8.62 \mathrm{E}-14$ \\
\hline immunoglobulin complex, circulating & $4.51 \mathrm{E}-12$ & $6.80 \mathrm{E}-13$ & $8.62 \mathrm{E}-14$ \\
\hline side of membrane & $2.04 \mathrm{E}-09$ & $3.83 \mathrm{E}-07$ & $3.22 \mathrm{E}-08$ \\
\hline cornified envelope & $9.30 \mathrm{E}-10$ & $2.14 \mathrm{E}-08$ & $6.68 \mathrm{E}-07$ \\
\hline
\end{tabular}

Table 5

GO Process terms significantly overexpressed in all 4T1 tumor locations. Two-sided, paired t-test p-value < 1E-06 for all 3 tumor locations simultaneously. Highlighted cells indicate maximal p-value between 3 areas.

\begin{tabular}{|llll|}
\hline Description & Center & Middle & Peripheral \\
& p-value & p-value & p-value \\
\hline translation & $1.42 \mathrm{E}-14$ & $9.60 \mathrm{E}-14$ & $2.20 \mathrm{E}-19$ \\
\hline peptide biosynthetic process & $9.80 \mathrm{E}-14$ & $8.59 \mathrm{E}-13$ & $1.99 \mathrm{E}-17$ \\
\hline cellular macromolecule biosynthetic process & $4.96 \mathrm{E}-12$ & $5.99 \mathrm{E}-15$ & $9.25 \mathrm{E}-17$ \\
\hline amide biosynthetic process & $3.74 \mathrm{E}-11$ & $2.47 \mathrm{E}-10$ & $4.08 \mathrm{E}-14$ \\
\hline macromolecule biosynthetic process & $3.13 \mathrm{E}-10$ & $3.06 \mathrm{E}-14$ & $2.39 \mathrm{E}-15$ \\
\hline peptide metabolic process & $6.68 \mathrm{E}-12$ & $1.22 \mathrm{E}-09$ & $1.53 \mathrm{E}-13$ \\
\hline cellular nitrogen compound biosynthetic process & $1.90 \mathrm{E}-08$ & $1.40 \mathrm{E}-09$ & $1.15 \mathrm{E}-10$ \\
\hline
\end{tabular}

Table 6

GO Function terms significantly overexpressed in all 4T1 tumor locations. Two-sided, paired t-test p-value < $1 \mathrm{E}-06$ for all 3 tumor locations simultaneously. Highlighted cells indicate maximal p-value between 3 areas.

\begin{tabular}{|llll|}
\hline Description & $\begin{array}{l}\text { Center } \\
\text { p-value }\end{array}$ & $\begin{array}{c}\text { Middle } \\
\text { p-value }\end{array}$ & $\begin{array}{l}\text { Peripheral } \\
\text { p-value }\end{array}$ \\
\hline RNA binding & $7.48 \mathrm{E}-14$ & $2.07 \mathrm{E}-21$ & $4.56 \mathrm{E}-26$ \\
\hline structural constituent of ribosome & $1.65 \mathrm{E}-13$ & $1.02 \mathrm{E}-17$ & $1.39 \mathrm{E}-32$ \\
\hline nucleic acid binding & $1.79 \mathrm{E}-10$ & $1.32 \mathrm{E}-21$ & $2.92 \mathrm{E}-24$ \\
\hline heterocyclic compound binding & $4.95 \mathrm{E}-08$ & $2.36 \mathrm{E}-14$ & $1.46 \mathrm{E}-12$ \\
\hline organic cyclic compound binding & $2.47 \mathrm{E}-07$ & $4.46 \mathrm{E}-13$ & $2.79 \mathrm{E}-11$ \\
\hline mRNA binding & $9.43 \mathrm{E}-07$ & $1.58 \mathrm{E}-09$ & $4.56 \mathrm{E}-14$ \\
\hline
\end{tabular}


Table 7

GO Component terms significantly overexpressed in all 4T1 tumor locations. Two-sided,

paired t-test $\mathrm{p}$-value $<1 \mathrm{E}-06$ for all 3 tumor locations simultaneously. Highlighted cells indicate maximal p-value between 3 areas.

\begin{tabular}{|llll|}
\hline Description & Center & Middle & Peripheral \\
\hline intracellular part & p-value & p-value & p-value \\
\hline ribosomal subunit & $1.46 \mathrm{E}-12$ & $1.02 \mathrm{E}-13$ & $1.26 \mathrm{E}-13$ \\
\hline cytosolic part & $6.01 \mathrm{E}-12$ & $3.36 \mathrm{E}-16$ & $2.33 \mathrm{E}-32$ \\
\hline ribosome & $3.61 \mathrm{E}-11$ & $3.48 \mathrm{E}-15$ & $4.12 \mathrm{E}-20$ \\
\hline ribonucleoprotein complex & $2.42 \mathrm{E}-10$ & $6.54 \mathrm{E}-15$ & $1.21 \mathrm{E}-26$ \\
\hline organelle & $2.75 \mathrm{E}-10$ & $6.04 \mathrm{E}-18$ & $5.50 \mathrm{E}-27$ \\
\hline intracellular organelle & $3.28 \mathrm{E}-09$ & $2.03 \mathrm{E}-09$ & $1.42 \mathrm{E}-11$ \\
\hline nucleus & $3.76 \mathrm{E}-09$ & $2.45 \mathrm{E}-09$ & $2.37 \mathrm{E}-12$ \\
\hline protein-containing complex & $1.02 \mathrm{E}-08$ & $1.15 \mathrm{E}-16$ & $6.31 \mathrm{E}-15$ \\
\hline cytoplasm & $1.36 \mathrm{E}-08$ & $2.87 \mathrm{E}-14$ & $6.26 \mathrm{E}-11$ \\
\hline intracellular non-membrane-bounded organelle & $3.47 \mathrm{E}-09$ & $2.17 \mathrm{E}-07$ & $1.42 \mathrm{E}-11$ \\
\hline non-membrane-bounded organelle & $4.92 \mathrm{E}-09$ & $3.06 \mathrm{E}-07$ & $1.58 \mathrm{E}-11$ \\
\hline
\end{tabular}

\section{Reproducibility of in vivo molecular harvesting with e-biopsy}

To study the reproducibility of our in vivo e-biopsy extraction method, we harvested liquids from 6 positions: 2 in the center, 2 in the middle, and 2 at the periphery (Fig. 1) from 4T1 tumors in vivo in 5 mice. In total, 4,262 proteins (with positive LFQ intensity in at least one e-biopsy sample) out of 4,519 total proteins were considered in this analysis. We found that the expression levels of proteins extracted from all locations in the tumor are highly correlated when comparing the location replicates (Table 8).

Table 8

E-biopsy reproducibility in vivo. Pearson and Spearman correlation coefficients of the LFQ intensities of e-biopsy-extracted proteins, at various position replicates from 4T1 tumor, as quantified by LCMS/MS. 4,262 proteins were considered from 5 mice (Fig. 1). All pvalues $<10 \mathrm{E}-324$

\begin{tabular}{|llll|}
\hline Location Replicates & Center & Middle & Periphery \\
\hline Average Pearson Correlation & 0.928 & 0.944 & 0.845 \\
\hline Average Spearman Correlation & 0.787 & 0.835 & 0.769 \\
\hline
\end{tabular}

In vivo e-biopsy supports mapping of 4T1 intratumor proteome spatial heterogeneity

To study the intratumor heterogeneity, we compared (two-sided, paired t-test) expression levels of proteins extracted in vivo by e-biopsy from three different tumor locations - center, midway, and periphery - in five animals. We found (Table S4) that 26 of 4,519 genes are significantly overexpressed, and 15 of 4,519 genes are significantly underexpressed in the center (compared to both other zones); 111 are overexpressed and 2 underexpressed in the middle; finally, 18 are overexpressed and 99 underexpressed at the periphery (significance here is defined by $\mathrm{p}$-value < 0.05). This represents FDR of 2.7e-01, $1.0 \mathrm{e}-01$ and $9.7 \mathrm{e}-02$ respectively (Methods).

Next, we intersected the genes from the above analysis (41 from the center, 113 from the middle and 117 from the periphery) with the set of 242 potential 4T1 biomarkers (over/under-expressed in each of three 4T1 tumor locations compared to healthy breast with p-value < 0.05, Methods and text before Table 1). We found (Table 9) 2 such genes in the center, 3 in the middle and 3 in the periphery. This represents FDR of 7.1e-4, 4.7e-4 and 4.7e-4 respectively (Methods).

Specifically, we found (Table 9) that the gene Glrx is significantly overexpressed in the 4T1 tumor center compared to the tumor's middle area and periphery (Fig. 3). We also found that Rbb7, Pkn1, and Ppme1 are overexpressed in the middle area of the tumor compared to its center and periphery (Fig. 3). No uniquely overexpressed potential tumor biomarker genes have been identified at the tumor periphery.

In the opposite direction, we found (Table 9) that the gene Ppme1 is significantly underexpressed in the 4T1 tumor center compared to tumor middle and tumor periphery (Fig. 3). Moreover, we found that Prkcsh, Tra2a, and Shoc2 are underexpressed at the tumor's periphery compared to 
its center and mid-zones (Fig. 3). No uniquely underexpressed potential tumor biomarker genes have been identified in the middle area tumor zone.

Table 9

Potential 4T1 tumor biomarkers that significantly differ (Methods) between three tumor areas. C - Center; M - Middle; P - Periphery; HB Healthy Breast

\begin{tabular}{|c|c|c|c|c|c|c|c|c|c|c|c|c|c|c|}
\hline \multirow[b]{2}{*}{ Area } & \multirow[b]{2}{*}{ Direction } & \multirow[b]{2}{*}{ Gene } & \multicolumn{2}{|l|}{ C vs $M$} & \multicolumn{2}{|l|}{ C vs $P$} & \multicolumn{2}{|c|}{$M$ vs $P$} & \multicolumn{2}{|c|}{ C vs NB } & \multicolumn{2}{|c|}{ M vs NB } & \multicolumn{2}{|c|}{ P vs NB } \\
\hline & & & $\begin{array}{l}\mathrm{p}- \\
\text { value }\end{array}$ & $\begin{array}{l}\mathrm{t}- \\
\text { stats }\end{array}$ & $\begin{array}{l}\mathrm{p}- \\
\text { value }\end{array}$ & $\begin{array}{l}\text { t- } \\
\text { stats }\end{array}$ & $\begin{array}{l}\mathrm{p}- \\
\text { value }\end{array}$ & $\begin{array}{l}\mathrm{t}- \\
\text { stats }\end{array}$ & $\begin{array}{l}\mathrm{p}- \\
\text { value }\end{array}$ & $\begin{array}{l}\mathrm{t}- \\
\text { stats }\end{array}$ & $\begin{array}{l}\mathrm{p}- \\
\text { value }\end{array}$ & $\begin{array}{l}\mathrm{t}- \\
\text { stats }\end{array}$ & $\begin{array}{l}\mathrm{p}- \\
\text { value }\end{array}$ & $\begin{array}{l}\text { t- } \\
\text { stats }\end{array}$ \\
\hline GIrx & UP & center & $\begin{array}{l}2.49 \mathrm{E}- \\
02\end{array}$ & 2.7 & 0.0 & 2.5 & \multicolumn{2}{|c|}{ not relevant } & $\begin{array}{l}2.25 \mathrm{E}- \\
03\end{array}$ & 7.0 & $\begin{array}{l}1.65 \mathrm{E}- \\
02\end{array}$ & 4.0 & $\begin{array}{l}4.91 \mathrm{E}- \\
02\end{array}$ & 2.8 \\
\hline Rbbp7 & UP & middle & $\begin{array}{l}8.82 \mathrm{E}- \\
03\end{array}$ & -3.3 & \multicolumn{2}{|c|}{ not relevant } & $\begin{array}{l}3.13 \mathrm{E}- \\
02\end{array}$ & 2.5 & $\begin{array}{l}3.51 \mathrm{E}- \\
02\end{array}$ & 3.1 & $\begin{array}{l}1.22 \mathrm{E}- \\
02\end{array}$ & 4.3 & $\begin{array}{l}4.43 \mathrm{E}- \\
02\end{array}$ & 2.9 \\
\hline Ppme1 & UP & middle & $\begin{array}{l}1.40 \mathrm{E}- \\
03\end{array}$ & -4.5 & \multicolumn{2}{|c|}{ not relevant } & $\begin{array}{l}7.46 \mathrm{E}- \\
04\end{array}$ & 5.0 & $\begin{array}{l}2.70 \mathrm{E}- \\
02\end{array}$ & 3.4 & $\begin{array}{l}1.25 \mathrm{E}- \\
02\end{array}$ & 4.3 & $\begin{array}{l}2.37 \mathrm{E}- \\
02\end{array}$ & 3.6 \\
\hline Pkn1 & UP & middle & $\begin{array}{l}1.24 \mathrm{E}- \\
02\end{array}$ & -3.1 & \multicolumn{2}{|c|}{ not relevant } & $\begin{array}{l}2.02 \mathrm{E}- \\
02\end{array}$ & 2.8 & $\begin{array}{l}4.91 \mathrm{E}- \\
02\end{array}$ & 2.8 & $\begin{array}{l}4.34 \mathrm{E}- \\
03\end{array}$ & 5.8 & $\begin{array}{l}3.55 \mathrm{E}- \\
02\end{array}$ & 3.1 \\
\hline Ppme1 & DOWN & center & $\begin{array}{l}1.40 \mathrm{E}- \\
03\end{array}$ & -4.5 & $\begin{array}{l}4.70 \mathrm{E}- \\
02\end{array}$ & -2.3 & \multicolumn{2}{|c|}{ not relevant } & $\begin{array}{l}2.70 \mathrm{E}- \\
02\end{array}$ & 3.4 & $\begin{array}{l}1.25 \mathrm{E}- \\
02\end{array}$ & 4.3 & $\begin{array}{l}2.37 \mathrm{E}- \\
02\end{array}$ & 3.6 \\
\hline Prkcsh & DOWN & periphery & \multicolumn{2}{|c|}{ not relevant } & $\begin{array}{l}2.09 \mathrm{E}- \\
02\end{array}$ & 2.8 & $\begin{array}{l}2.08 \mathrm{E}- \\
02\end{array}$ & 2.8 & $\begin{array}{l}1.01 \mathrm{E}- \\
02\end{array}$ & 4.6 & $\begin{array}{l}2.55 \mathrm{E}- \\
02\end{array}$ & 3.5 & $\begin{array}{l}2.68 \mathrm{E}- \\
02\end{array}$ & 3.4 \\
\hline Tra2a & DOWN & periphery & \multicolumn{2}{|c|}{ not relevant } & $\begin{array}{l}2.33 \mathrm{E}- \\
02\end{array}$ & 2.7 & $\begin{array}{l}1.75 \mathrm{E}- \\
02\end{array}$ & 2.9 & $\begin{array}{l}3.70 \mathrm{E}- \\
02\end{array}$ & 3.1 & $\begin{array}{l}1.77 \mathrm{E}- \\
02\end{array}$ & 3.9 & $\begin{array}{l}1.77 \mathrm{E}- \\
02\end{array}$ & 3.9 \\
\hline Shoc2 & DOWN & periphery & \multicolumn{2}{|c|}{ not relevant } & $\begin{array}{l}1.02 \mathrm{E}- \\
02\end{array}$ & 3.2 & $\begin{array}{l}3.42 \mathrm{E}- \\
02\end{array}$ & 2.5 & $\begin{array}{l}4.02 \mathrm{E}- \\
03\end{array}$ & 5.9 & $\begin{array}{l}2.02 \mathrm{E}- \\
02\end{array}$ & 3.7 & $\begin{array}{l}2.17 \mathrm{E}- \\
02\end{array}$ & 3.7 \\
\hline
\end{tabular}

The distribution of the observed differential expression scores, computed from comparing protein measurements between 4T1 tumor locations, is statistically significant (Fig. 4). The overabundance plots show that more differentially expressed proteins are observed in our data than would be expected under a random null model ${ }^{43}$. We also show that in vivo measurements obtained by e-biopsy are consistent with those obtained from the standard ex vivo lysis method (Supplementary information).

Gene Ontology (GO) analysis of 4,519 e-biopsy-extracted proteins was used to further examine the differential expression between all three locations in the 4T1 tumor in terms of various cellular processes, functions, and components. Here we present the most significant (p-value < 1e06 at each location simultaneously) differentially regulated processes, functions, and components (Table 10) and discuss several interesting observations. All the identified processes, functions, and components that differ with p-value < $1 \mathrm{e}-06$ are presented online in https://github.com/GolbergLab/eBiopsy4T1. In the comparison between Center and Periphery, no significant overexpressed function and components were identified in the Center. In the comparison between Middle and Periphery, no significant overexpressed processes, functions, and components were identified in the Middle (all three were overexpressed at the Periphery). 
Table 10

GO terms significantly differentially regulated per each 4T1 tumor location. Two-sided, paired t-test $p$-value $<1 \mathrm{e}-06$ with two other tumor locations simultaneously.

\begin{tabular}{|c|c|c|c|c|c|}
\hline Region & Direction & Description & $\begin{array}{l}\text { Center } \\
\text { p-value }\end{array}$ & $\begin{array}{l}\text { Middle } \\
\text { p-value }\end{array}$ & $\begin{array}{l}\text { Peripheral } \\
\text { p-value }\end{array}$ \\
\hline Center & High & PROCESS: blood coagulation & & $6.96 \mathrm{E}-09$ & 4.94E-07 \\
\hline Center & High & PROCESS: coagulation & & $6.96 \mathrm{E}-09$ & 4.94E-07 \\
\hline Center & Low & PROCESS: cytoplasmic translation & & $1.90 \mathrm{E}-11$ & 5.60E-08 \\
\hline Center & Low & FUNCTION: structural constituent of ribosome & & $8.60 \mathrm{E}-11$ & 5.36E-12 \\
\hline Center & Low & COMPONENT: cytosolic large ribosomal subunit & & $1.42 \mathrm{E}-11$ & $1.54 \mathrm{E}-12$ \\
\hline Center & Low & COMPONENT: ribosomal subunit & & 9.67E-11 & $1.02 \mathrm{E}-11$ \\
\hline Center & Low & COMPONENT: ribosome & & $2.81 \mathrm{E}-11$ & 4.06E-10 \\
\hline Center & Low & COMPONENT: cytosolic part & & 1.83E-11 & $2.52 \mathrm{E}-09$ \\
\hline Center & Low & COMPONENT: cytoplasmic part & & $5.45 \mathrm{E}-09$ & 2.33E-08 \\
\hline Center & Low & COMPONENT: ribonucleoprotein complex & & $2.78 \mathrm{E}-14$ & 3.03E-08 \\
\hline Center & Low & COMPONENT: large ribosomal subunit & & 1.27E-07 & $1.59 \mathrm{E}-08$ \\
\hline Center & Low & COMPONENT: intracellular & & $1.44 \mathrm{E}-09$ & 5.09E-07 \\
\hline Periphery & High & COMPONENT: cytoplasmic part & 2.33E-08 & 7.71E-07 & \\
\hline
\end{tabular}

Notably, in analyzing GO terms we found a significant decrease in ribosomal activity toward the 4T1 tumor's central region. This finding is consistent with previous work that showed that tumorigenicity was associated with profound alterations in ribosomal biogenesis and function, leading to the decreased translation of mRNA of tumor suppressor p53 and the reduced control of translational fidelity ${ }^{48}$. Also, GO analysis yielded a significant increase in blood coagulation toward the center of the tumor, consistent with increased vacularisation ${ }^{49}$.

The findings above show that proteomic profiling of in vivo e-biopsy samples can detect and potentially characterize 4T1 tumor heterogeneity. Specifically, the differences in protein expression profiles for the different sampled tumor regions are statistically significant. In addition, we identified enriched biological changes in cellular processes, functions, and components when comparing the 4T1 tumor's center, middle, and periphery regions.

\section{Discussion}

Current cancer treatment decisions are often based on the information obtained from an aspiration needle biopsy or a surgical excision. These excised samples are evaluated for histopathology. Sometimes molecular tests are used to obtain more precise diagnostic results ${ }^{25}$. Standard treatment of patients with metastatic disease is usually based on predictive biomarkers detected with the original biopsy, which often does not fully reflect the status of disease progression ${ }^{25}$. Moreover, multiple recent studies suggest that tumor biopsies may vastly underrepresent tumors' heterogeneity and, therefore, may miss the drug-resistant clones $24,25,50,51$. In this work, we report a new method to probe tumors using molecular harvesting with electroporation, termed e-biopsy. Electroporation changes the permeabilization of the cell membrane, consequently increasing the accessibility of intracellular compounds ${ }^{30}$. In this work, we show that in vivo e-biopsy extraction of proteins yields a characteristic signature of 4T1 tumors vs healthy breast tissue in mice. We moreover show that point e-biopsy can detect various proteomic signatures in various geographical locations of the same tumor, thus increasing our understanding of the tumor sub-clonal spatial composition (Fig. 3, Fig. 4). As e-biopsy is potentially less aggressive than the current standard excision-based biopsy method, this technology can serve as a basis for new diagnostic approaches that will better address tumor heterogeneity, by probing tumors in multiple locations.

Molecular harvesting by e-biopsy can distinguish between 4T1 tumor and healthy breast tissues, regardless of sampling location. We found 13 strongly overexpressed proteins (Table 1) in all sampled 4T1 tumor locations simultaneously. Some of these 13 proteins are known to have profound roles in breast cancer. For example, Vimentin (Vim), is considered a marker for epithelial-to-mesenchymal transition ${ }^{52}$. Long noncoding RNA (IncRNA), including VIM-AS1, and AGAP2-AS1 regulate Vim's expression. Vim overexpression was reported in breast tumors in previous studies ${ }^{53}$. In addition, Hnrnpa21b overexpression was reported in endocrine-resistant LCC9 breast cancer cells. ${ }^{54}$ Furthermore, triplenegative breast cancer patients face resistance to the drug trastuzumab by the active involvement of Polyadenylate-binding protein 1 (Pabpc1), expression of which is induced by overexpression of SNHG14 ${ }^{55}$. For Serpinh1, also known as Hsp47, expression activation was reported during breast cancer development and progression ${ }^{56}$. Previous studies also demonstrated overexpression of hnRNPA1 during breast cancer 
progression ${ }^{57}$. Slc25a24, Cnpy2 and BAX overexpression was reported in breast cancer ${ }^{58}$. Similar to our work, a recent study reported on the overexpression of Plin3 in the breast cancer tissues in comparison with normal breast ${ }^{59}$. HMGB1 is considered a ubiquitous protein, which has a role as a nuclear cofactor in the regulation of transcription ${ }^{60}$. HMGB1 overexpression in breast cancer tissue indicates metastasis, TNM stage, and differentiation ${ }^{61}$. HMBG1 has a promising role in breast cancer management as it affects chemotherapy, immunotherapy, and radiotherapy ${ }^{62}$. Mat2b overexpression was observed in the triple negative breast cancer ${ }^{63}$. In summary, this comparison to literature analysis showed that 11 out of 13 proteins that were extracted with e-biopsy in vivo and measured as overexpressed have been reported as overexpressed in breast cancer in previous studies using other extraction and quantification methods.

Drug resistance is one of the major hurdles in cancer treatment ${ }^{64,65}$. There are several known resistance mechanisms, with heterogeneity in tumors being one of the most important amongst them ${ }^{26}$. Our work, using $4 \mathrm{~T} 1$ as a model, shows that e-biopsy may help in charting and quantifying the heterogeneity in tumors, mapping over- and underexpressed genes spatially, and thereby leading to in vivo low resolution molecular tumor cartography. In Table 9, Table 10, Fig. 3, and Table S4, we show an example of such a map based on differentially expressed genes in three spatial zones of a $4 \mathrm{~T} 1$ tumor.

In addition to individual gene expression analysis, we also performed a gene ontology (GO) enrichment analysis of the measured proteome extracted by e-biopsy and of the inferred differential proteomics. GO analysis revealed that overexpression and underexpression of biological processes (Table 2, 5), functions (Table 3,6) and components (Table 4,7) in 4T1 tumor, in comparison with the healthy breast samples, is similar to previously published GO studies on $4 \mathrm{~T} 1^{66-69}$, where the molecules were harvested with other methods. Analyzing the Gene Ontology for $4 \mathrm{~T} 1$ in depth provides insight into difference between the tumor and the healthy breast and the tumor's various locations (Center, Middle, Periphery), and therefore suggests tumor heterogeneity for these studied samples (Table 9, Table 10). Similar to our work, published literature on $4 \mathrm{~T} 166,68$ corroborates these findings. Altogether, the pathway enrichment analysis suggests that the proteomic profile detected by e-biopsy is corroborated by similar reports in the literature using other extraction methods. We, therefore, expect e-biopsy sampling to potentially yield biological information which is equivalent, at the level of gene sets or pathways, to that which would be inferred by other sampling technologies.

\section{Conclusions}

In the current work we introduce e-biopsy, a novel tool for molecular harvesting in vivo using electroporation. E-biopsy has the potential to reduce the risks and morbidities of excision biopsy and to provide additional information and better profiling of the tumor and the probed environment in vivo. We demonstrate that e-biopsy enables the in vivo distinction between tumor and non-tumor samples and locations in the $4 \mathrm{~T} 1$ mice model. Due to its minimal invasive nature, e-biopsy can potentially enable tumor sampling at multiple locations. We therefore hope that e-biopsy will potentially facilitate shedding light on the clonal subpopulation composition of tumors. This information on the tumor's heterogeneity may be vitally important for higher precision personalized therapies. We therefore believe that e-biopsy represents a useful addition to the toolbox available to scientists and practitioners in their approach to treating cancer patients.

\section{Methods}

\section{Animals}

All animal procedures were approved by the Israel National Council for Animal Experimentation (Study no. IL-19-3-114). Five 8-week-old female Balb/c female mice weighing $\sim 20 \mathrm{~g}$ were provided by the Science in Action, Ltd. CRO. The animals were housed in cages with access to food and water ad libitum and were maintained on a $12 \mathrm{~h}$ light/dark cycle at a room temperature of $\sim 21^{\circ} \mathrm{C}$ and a relative humidity of $30 \%-70 \%$. All in vivo experiments were conducted by a professional veterinarian as per Israel National Council for Animal Experimentation guidelines and regulations.

In vivo 4 T1 tumor model

4T1 cell line was purchased from the American Type Culture Collection (Manassas, VA, USA). The cells were cultured in RPMI-1640 media with L-Glutamine supplemented with $10 \%$ fetal bovine serum (FBS), $0.11 \mathrm{mg} / \mathrm{ml}$ sodium pyruvate, $100 \mathrm{U} / \mathrm{ml}$ penicillin, and $100 \mu \mathrm{g} / \mathrm{ml}$ streptomycin (Biological Industries, Israel) at $37^{\circ} \mathrm{C}$ in a humidified $\mathrm{CO}_{2}$ incubator. $4 \mathrm{~T} 1$ cells were subcutaneously injected $\left(0.5 \mathrm{X} 10^{6} \mathrm{cells}\right)$ into Balb/c female mice.

\section{Histology}

Specimens were harvested immediately after the treatment and fixed in 10\% formalin. Samples in plastic cassettes were dehydrated through ascending ethanol concentrations, transferred into xylene, and then paraffinized, by an automated machine. Next, the samples were manually embedded into paraffin blocks. The paraffin blocks were sectioned at approximately 3-5 microns thickness. Sections were placed on glass slides. Slides were stained with Hematoxylin \& Eosin (H\&E) and covered by an automated machine.

Page $10 / 19$ 


\section{Immunohistochemistry}

Paraffin blocks were sectioned at approximately 3-5 microns thickness. Sections were placed on SuperFrost Plus ${ }^{\text {TM }}$ glass slides. Slides were incubated overnight at $60^{\circ} \mathrm{C}$. Slides were stained using the standard procedure in Ventana BenchMark Ultra automated slide stainer in combination with Ventana UltraView Universal DAB Detection Kit (Ventana, Roche Diagnostics cat \#760-500). The slides were stained with the following antibodies: monoclonal mouse anti-Human Ki-67, clone MIB-1 (Dako, cat\# M7240), diluted 1:200, and monoclonal mouse anti-Human Glypican-3 (GPC3), clone 1G12 (BioCare Medical, and cat\# PM396 AA), ready to use. Slides were counterstained in Mayer's Hematoxylene, dehydrated through ascending ethanol concentrations, cleared in Xylene, mounted, and covered.

\section{Pulsed electric field application for protein extraction in vivo}

E-biopsy was performed with a $23 \mathrm{G}$ needle at 6 positions inside each tumor: 2 in the center, 2 at the periphery, and 2 in the middle between the center and the periphery (Fig. 1). The needle was connected to a cathode. The second $23 \mathrm{G}$ needle, connected to the anode, was held at a $1 \mathrm{~cm}$ distance from the first needle. The pulsed electric field was applied using the electric field pulse generator (BTX830, Harvard Apparatus, MA). Electroporation was performed using a combination of high-voltage short pulses with low-voltage long pulses as follows: 40 pulses $1000 \mathrm{~V}$, $40 \mu \mathrm{s}, 4 \mathrm{~Hz}$, and 40 pulses $150 \mathrm{Vcm}^{-1}, 15 \mathrm{~ms}$, delivered at $4 \mathrm{~Hz}$. After the PEF treatment, the liquids were extracted from the tissue to the needle applied to a vacuum with a $1.5 \mathrm{~mL}$ syringe. The liquids were immediately transferred to $1.5 \mathrm{ml}$ tubes with $100 \mu \mathrm{l}$ double distilled water (DDW). Isolating proteins from the pulsed electric field extracted juices

Proteins were isolated from the PEF extract using the protocol of the EZ- RNA II kit (Biological Industries Beit Haemek, Ltd, Israel). For protein isolation from PEF samples, the liquids from tissue after electroporation were added to $100 \mathrm{ul}$ of DDW. Homogenizing solutions were not used in PEF samples; instead, phase separation solutions were directly added: $0.2 \mathrm{ml}$ of water-saturated phenol and $0.045 \mathrm{ml}$ of bathocuproine (BCP) buffer. Air-dried protein pellets were taken for proteomic analysis as described below.

\section{Isolating proteins from tissue using lysis buffer}

Proteins were isolated using the protocol of the EZ- RNA II kit (Biological Industries Beit Haemek, Ltd, Israel). Tissue samples were homogenized in the Denaturing Solution (0.5ml/50-100mg tissue) using Bead Beater (Biospec, OK). Then $0.4 \mathrm{ml}$ of water-saturated phenol and $0.09 \mathrm{ml}$ of BCP were added. Air-dried protein pellets were taken for proteomic analysis as described below.

\section{Identifying and quantifying proteins using LC-MS/MS \\ Proteolysis}

The samples were brought to $8 \mathrm{M}$ urea, $400 \mathrm{mM}$ ammonium bicarbonate, $10 \mathrm{mM}$ DTT, vortexed, sonicated for $5^{\prime}$ at $90 \%$ with $10-10$ cycles, and centrifuged. The protein amount was estimated using Bradford readings. 20ug protein from each sample was reduced at $60^{\circ} \mathrm{C}$ for $30 \mathrm{~min}$, modified with $37.5 \mathrm{mM}$ iodoacetamide in $400 \mathrm{mM}$ ammonium bicarbonate (in the dark at room temperature for $30 \mathrm{~min}$ ), and digested in $2 \mathrm{M}$ Urea and $100 \mathrm{mM}$ ammonium bicarbonate with modified trypsin (Promega,WI) at a 1:50 enzyme-to-substrate ratio, overnight at $37^{\circ} \mathrm{C}$. An additional second digestion with trypsin was done for 4 hours at $37^{\circ} \mathrm{C}$.

\section{Mass spectrometry analysis}

The tryptic peptides were desalted using C18 tips (Harvard Apparatus,MA), dried, and re-suspended in $0.1 \%$ formic acid. The peptides were resolved by reverse-phase chromatography on 0.075 X 180-mm fused silica capillaries (J\&W) packed with Reprosil reversed-phase material (Dr. Maisch $\mathrm{GmbH}$, Germany). The peptides were eluted with a linear 180 -minute gradient of 5 to $28 \%, 15$ minutes' gradient of 28 to $95 \%$, and 25 minutes at $95 \%$ acetonitrile with $0.1 \%$ formic acid in water at flow rates of $0.15 \mu \mathrm{l} / \mathrm{min}$. Mass spectrometry was performed using Q-Exactive Plus mass spectrometer (ThermoFischer Scientific, CA) in a positive mode using a repetitively full MS scan followed by collision-induced dissociation (HCD) of the 10 most dominant ions selected from the first MS scan.

The mass spectrometry data from all biological repeats were analyzed using MaxQuant software 1.5.2.8 vs. the mouse proteome from the UniProt database with $1 \%$ FDR. The data were quantified by label-free analysis using the same software, based on extracted ion currents (XICs) of peptides, enabling quantitation from each LC/MS/MS run for each peptide identified in any of the experiments.

\section{Bioinformatics and statistical analysis}

Data for 4,781 proteins was obtained from the mass spectrometry analysis, 4,519 of which were accompanied by valid protein and gene ids. LFQ-intensity normalization for these 4,519 proteins, as obtained from MaxQuant 1.5.2.8 was used in all bioinformatics analyses.

\section{Inter-sample correlation analysis}


Pearson and Spearman correlations were estimated between LFQ-intensity protein profiles of each sample with scipy.stats.pearsonrand scipy.stats.spearmanr functions respectively (Fig. S2, Table S2).

To count the identified proteins (Table S1, Table S5) by each method (e-biopsy vs Lysis), we defined all proteins with strictly positive LFQintensity as existing within the specific sample (any sample in case of Location_MIX). If a protein was identified by e-biopsy/lysis only, it was marked as uniquely captured by e-biopsy/lysis. Otherwise (protein LFQ-intensity $>0$ measured by both methods) it was marked as simultaneously captured by both methods. The value for Mouse_Average was derived as an average of all of the comparisons of samples within the same mouse.

\section{Differential expression analysis of control (healthy breast) and tumor (4T1) samples}

The protein representations for control were constructed as 5D vectors based on e-biopsy LFQ-intensity measurements from healthy breast tissue in 5 mice. The protein representations for tumors were constructed as 5D vectors based on the average of two LFQ-intensity measurement replicas at specific 4T1 tumor locations from 5 mice. Paired two-tail Student $t$-test was performed with scipy.stats.ttest_rel function. Further, the overabundance comparison of the obtained distribution to the random model was performed ${ }^{43}$ (Fig. 2 ). 13 genes with Student $t$-test p-values below 0.01 at each location simultaneously (73 such genes were identified in Peripheral, 160 in Middle and 164 in Center) were labelled as strongly overexpressed (no underexpressed genes for the same criteria were identified) in breast cancer tissue (Table 1). The intersection of this size has a p-value below 1.15e-06, which is an upper limit based on Hypergeometric tail (HGT) with parameters $(4519,160,73,13)$. These 13 proteins therefore represent an FDR of $4519 \bullet\left(0.01^{\wedge} 3\right) / 13=3.5 e-04$. The same process at Student $t$-test $p$-value of 0.05 results in a set of 242 genes (238 overexpressed and 4 under-expressed), corresponding to False Discovery Rate (FDR) of $4519 \bullet\left(0.05^{\wedge} 3\right) / 242=2.3 e-03$. In the further analysis we call these 242 differentially expressed proteins - potential 4T1 biomarkers, specifically for the subsequent search for intra-tumor heterogeneity markers, particularly for filtering out Table 9 from Table S4.

\section{Intratumor differential expression analysis}

The protein representations for all tumor locations were constructed as 10D vectors based on e-biopsy LFQ-intensity measurements from two replicas at specific tumor locations in 5 mice. Paired two-tail Student $t$-test was performed with scipy.stats.ttest_re/ function. Then, the overabundance comparison of the obtained distribution to the random model was performed ${ }^{43}$ (Fig. 4).

Genes with Student $t$-test p-values below 0.05 with differential regulation in one zone compared to both others were extracted (Table S4). Specifically, for the up-regulation direction we tested for central location: both center $>$ middle and center $>$ periphery (26 such genes); for middle location: both center < middle and middle > periphery (111 such genes); and for peripheral location: both center < periphery and middle < periphery (18 such genes). The same analysis process was performed in the opposite directions for the down-regulation direction, resulting in 15,2 and 99 genes respectively. These findings represent FDR of $4519 \bullet\left(0.05^{\wedge} 2\right) /(26+15)=2.7 e-01,4519 \bullet\left(0.05^{\wedge} 2\right) /(111+2)=1.0 e-01$ and $4519 \bullet\left(0.05^{\wedge} 2\right) /(18+99)=9.7 e-02$ respectively. Next, the resultant genes were intersected with 242 potential biomarker candidates, and the results labelled as heterogeneously expressed in breast cancer tissue (Table 9, Fig. 3). We identified 2 such genes in the center, 3 in the middle and 3 in the periphery, that corresponds to FDR of $4519 \bullet\left(0.05^{\wedge} 2\right) \cdot\left(0.05^{\wedge} 3\right) / 2=7.1 \mathrm{e}-4,4519 \bullet\left(0.05^{\wedge} 2\right) \bullet\left(0.05^{\wedge} 3\right) / 3=4.7 \mathrm{e}-4,4519 \bullet\left(0.05^{\wedge} 2\right) \bullet\left(0.05^{\wedge} 3\right) / 3=4.7 \mathrm{e}-4$ respectively.

\section{Gene Ontology analysis}

The proteins detected simultaneously in both tissues/locations were sorted as per their Student $t$-test t-statistic values (in decreasing direction for overexpression, and increasing direction for underexpression). Then cellular processes, functions, and components based on Gene Ontology (GO) were tested for significant ( $\mathrm{mHG}$ p-value < 1e-06) overabundance at the top of the obtained proteins list using Gorilla tool ${ }^{70,71,72 .}$

GO analysis results for pairwise analysis of different 4T1 tumor Center, Periphery and Healthy breast appear online in https://github.com/GolbergLab/eBiopsy4T1.

\section{Abbreviations}

e-biopsy- molecular harvesting by electroporation

GO- Gene Ontology

mHG- minimum-hypergeometric test

GOrilla- Gene Ontology enRIchment anaLysis and visuaLizAtion tool

FDR- false discovery rate

Page 12/19 
HGT - Hypergeometric tail

LFQ -label-free quantitation

PEF- pulsed electric field

H\&E - Hematoxylin \& Eosin

\section{Declarations}

\section{Ethical Approval and Consent to participate}

Not applicable

Consent for publication

All authors gave their consent for publication.

\section{Availability of supporting data}

The authors hereby declare that all data supporting the findings of this study are available within the paper, its Supplementary Information and Online in https://github.com/GolbergLab/eBiopsy4T1.

\section{Competing interests}

A patent application was filed to protect the technology described herein as invented by AG, JS, and ZY.

\section{Funding}

The authors thank the Israel Ministry of Science and Technology, the TAU SPARK fund, and the EuroNanoMed MATISSE project for their support of this project.

\section{Authors' contributions}

Edward Vitkin: analyzed the data, drafted the paper

Amrita Singh: performed experiments, analyzed the data, drafted the paper

Julia Wise: conceived the study, performed experiments, analyzed the data, drafted the paper

Shay Ben-Elazar: analyzed the data

Zohar Yakhini: conceived the study, analyzed the data, drafted the paper

Alexander Golberg: conceived the study, performed experiments, analyzed the data, drafted the paper

\section{Acknowledgements}

All authors thank the members of the Smoler Proteomics Center at the Faculty of Biology at the Technion. We specifically thank Keren Bendalak for her help with the LC-MS/MS analysis. All authors thank Raanan Margalit from Science in Action, Ltd. for help with animal experiments.

\section{Authors' information}

Edward Vitkin: edward.vitkin@gmail.com

Amrita Singh: amritasvp52@gmail.com

Julia Wise: julia.wise905@gmail.com

Shay Ben-Elazar: shay.benel@gmail.com

Zohar Yakhini: zohar.yakhini@idc.ac.il

Alexander Golberg: agolberg@gmail.com

\section{References}

1. Chapman PB, et al. Improved survival with vemurafenib in melanoma with BRAF V600E mutation. N Eng J Med. 2011;364:2507-16. 
2. Chan BA, Hughes BG. Targeted therapy for non-small cell lung cancer: current standards and the promise of the future. Transl Lung Cancer Res. 2015;4:36-54.

3. Ellis PM, Coakley N, Feld R, Kuruvilla S, Ung YC. Use of the epidermal growth factor receptor inhibitors gefitinib, erlotinib, afatinib, dacomitinib, and icotinib in the treatment of non-small-cell lung cancer: a systematic review. Curr Oncol. 2015;22:e183-215.

4. Bittner M, et al. Molecular classification of cutaneous malignant melanoma by gene expression profiling. Nature. 2000;406:536-40.

5. Hedenfalk I, et al. Gene-Expression Profiles in Hereditary Breast Cancer. N Engl J Med. 2001;344:539-48.

6. Haakensen VD, et al. Serum N-glycan analysis in breast cancer patients - Relation to tumour biology and clinical outcome. Mol Oncol. 2016;10:59-72.

7. Golub TR, et al Molecular classification of cancer: Class discovery and class prediction by gene expression monitoring. Science (80-.). (1999). doi:10.1126/science.286.5439.531.

8. Ludwig JA, Weinstein JN. Biomarkers in cancer staging, prognosis and treatment selection. Nat Rev Cancer. 2005;5:845-56.

9. Massuti B, Sanchez JM, Hernando-Trancho F, Karachaliou N, Rosell R. Are we ready to use biomarkers for staging, prognosis and treatment selection in early-stage non-small-cell lung cancer? Transl lung cancer Res. 2013;2:208-21.

10. Alieva M, et al. Preventing inflammation inhibits biopsy-mediated changes in tumor cell behavior. Sci Rep. 2017. doi:10.1038/s41598-01707660-4.

11. Exner GU, Kurrer MO, Mamisch-Saupe N, Cannon SR. The tactics and technique of musculoskeletal biopsy. EFORT Open Rev. $2017 ; 2: 51-7$.

12. Alieva M, van Rheenen J, Broekman ML. D. Potential impact of invasive surgical procedures on primary tumor growth and metastasis. Clin Exp Metastasis. 2018;35:319-31.

13. Mathenge EG, et al. Core Needle Biopsy of Breast Cancer Tumors Increases Distant Metastases in a Mouse Model. Neoplasia. 2014. doi:10.1016/j.neo.2014.09.004.

14. Sennerstam RB, Franzén BSH, Wiksell HOT, Auer GU. Core-needle biopsy of breast cancer is associated with a higher rate of distant metastases 5 to 15 years after diagnosis than FNA biopsy. Cancer Cytopathol. 2017. doi:10.1002/cncy.21909.

15. Tosoian JJ, Antonarakis ES Molecular heterogeneity of localized prostate cancer: more different than alike. Transl. Cancer Res. Vol 6, Suppl. 1 (February 2017) Transl. Cancer Res. (2017). doi:10.21037/tcr.2017.02.17.

16. Wei L, et al. Intratumoral and Intertumoral Genomic Heterogeneity of Multifocal Localized Prostate Cancer Impacts Molecular Classifications and Genomic Prognosticators. Eur Urol. 2017;71:183-92.

17. Gerlinger M, et al. Intratumor heterogeneity and branched evolution revealed by multiregion sequencing. N Engl J Med. 2012;366:883-92.

18. Tannock IF, Hickman JA. Limits to Personalized Cancer Medicine. N Engl J Med. 2016;375:1289-94.

19. Ellsworth RE, Blackburn HL, Shriver CD, Soon-Shiong P, Ellsworth DL. Molecular heterogeneity in breast cancer: State of the science and implications for patient care. Semin Cell Dev Biol. 2017;64:65-72.

20. Thomsen $\mathrm{MBH}$, et al. Comprehensive multiregional analysis of molecular heterogeneity in bladder cancer. Sci. Rep. 7, (2017).

21. Levy-Jurgenson A, Tekpli X, Kristensen VN, Yakhini Z. Spatial transcriptomics inferred from pathology whole-slide images links tumor heterogeneity to survival in breast and lung cancer. Sci Rep. 2020. doi:10.1038/s41598-020-75708-z.

22. Bedard PL, Hansen AR, Ratain MJ, Siu L. L. Tumour heterogeneity in the clinic. Nature. 2013. doi:10.1038/nature12627.

23. Martín-Pardillos A, et al. The role of clonal communication and heterogeneity in breast cancer. BMC Cancer. 2019. doi:10.1186/s12885-0195883-y.

24. Russo M, et al. Tumor heterogeneity and Lesion-Specific response to targeted therapy in colorectal cancer. Cancer Discov. 2016. doi:10.1158/2159-8290.CD-15-1283.

25. Parikh AR, et al. Liquid versus tissue biopsy for detecting acquired resistance and tumor heterogeneity in gastrointestinal cancers. Nat Med. 2019. doi:10.1038/s41591-019-0561-9.

26. Dagogo-Jack I, Shaw AT. Tumour heterogeneity and resistance to cancer therapies. Nature Reviews Clinical Oncology. 2018;15:81-94.

27. Ofiara LM, Navasakulpong A, Beaudoin S, Gonzalez AV. Optimizing Tissue Sampling for the Diagnosis, Subtyping, and Molecular Analysis of Lung Cancer. Front. Oncol. 4, (2014).

28. Cyll K, et al. Tumour heterogeneity poses a significant challenge to cancer biomarker research. Br J Cancer. 2017;117:367-75.

29. Zhang J, et al. Nondestructive tissue analysis for ex vivo and in vivo cancer diagnosis using a handheld mass spectrometry system. Sci Transl Med. 2017. doi:10.1126/scitranslmed.aan3968.

30. Yarmush ML, Golberg A, Serša G, Kotnik T, Miklavčič D. Electroporation-Based Technologies for Medicine: Principles, Applications, and Challenges. Annu Rev Biomed Eng. 2014;16:295-320.

31. Golberg A, Rubinsky B. Towards electroporation based treatment planning considering electric field induced muscle contractions. Technol Cancer Res Treat. 2012;11:189-201.

Page $14 / 19$ 
32. Kos B, Voigt P, Miklavcic D, Moche M. Careful treatment planning enables safe ablation of liver tumors adjacent to major blood vessels by percutaneous irreversible electroporation (IRE). Radiol Oncol. 2015;49:234-41.

33. Garcia PA, Davalos RV, Miklavcic DA. Numerical Investigation of the Electric and Thermal Cell Kill Distributions in Electroporation-Based Therapies in Tissue. PLoS One. 2014;9:e103083.

34. Groselj A, et al. Coupling treatment planning with navigation system: a new technological approach in treatment of head and neck tumors by electrochemotherapy. Biomed Eng Online. 2015;14:2.

35. Zupanic A, Kos B, Miklavcic D. Treatment planning of electroporation-based medical interventions: Electrochemotherapy, gene electrotransfer and irreversible electroporation. Phys Med Biol. 2012. doi:10.1088/0031-9155/57/17/5425.

36. Pavliha D, Mušič MM, Serša G, Miklavčič D. Electroporation-Based Treatment Planning for Deep-Seated Tumors Based on Automatic Liver Segmentation of MRI Images. PLoS One. 2013. doi:10.1371/journal.pone.0069068.

37. Polikovsky M, et al. Towards marine biorefineries: Selective proteins extractions from marine macroalgae Ulva with pulsed electric fields. Innov Food Sci Emerg Technol. 2016;37:194-200.

38. Robin A, et al. Deashing macroalgae biomass by pulsed electric field treatment. Bioresour Technol. 2018;255:131-9.

39. Polikovsky M, et al. In silico food allergenic risk evaluation of proteins extracted from macroalgae Ulva sp. with pulsed electric fields. Food Chem. 2019;276:735-44.

40. Edd JF, Horowitz L, Davalos RV, Mir LM, Rubinsky B. In vivo results of a new focal tissue ablation technique: Irreversible electroporation. IEEE Trans Biomed Eng. 2006. doi:10.1109/TBME.2006.873745.

41. Golberg A, Bruinsma BG, Jaramillo M, Yarmush M, Uygun BE. Rat liver regeneration following ablation with irreversible electroporation. PeerJ (2016).

42. Djokic M, et al. Electrochemotherapy as treatment option for hepatocellular carcinoma, a prospective pilot study. Eur J Surg Oncol. 2018. doi:10.1016/j.ejso.2018.01.090.

43. Ben-Dor Friedman N, Yakhini Z, A. Overabundance Analysis and Class Discovery in Gene Expression Data. (Submitted) (2003). doi:10.1344/MUSAS2017.VOL2.NUM2.4.

44. Carmi Y, et al. Allogeneic IgG combined with dendritic cell stimuli induce antitumour T-cell immunity. Nature. 2015. doi:10.1038/nature14424.

45. Yang F, et al. Inhibition of dipeptidyl peptidase-4 accelerates epithelial-mesenchymal transition and breast cancer metastasis via the CXCL12/CXCR4/mTOR axis. Cancer Res. 2019. doi:10.1158/0008-5472.CAN-18-0620.

46. Zhang Y, et al. Elemene inhibits the migration and invasion of 4T1 murine breast cancer cells via heparanase. Mol Med Rep. 2017. doi:10.3892/mmr.2017.6638.

47. Jose C, Bellance N, Rossignol R. Choosing between glycolysis and oxidative phosphorylation: A tumor's dilemma? Biochimica et Biophysica Acta - Bioenergetics. 2011. doi:10.1016/j.bbabio.2010.10.012.

48. Belin S, et al. Dysregulation of ribosome biogenesis and translational capacity is associated with tumor progression of human breast cancer cells. PLoS One. 2009. doi:10.1371/journal.pone.0007147.

49. Kim C, et al. Spatiotemporal heterogeneity of tumor vasculature during tumor growth and antiangiogenic treatment: MRI assessment using permeability and blood volume parameters. Cancer Med. 2018. doi:10.1002/cam4.1624.

50. McGranahan N, Swanton C. Biological and therapeutic impact of intratumor heterogeneity in cancer evolution. Cancer Cell. 2015. doi:10.1016/j.ccell.2014.12.001.

51. Piotrowska Z, et al. Heterogeneity and Coexistence of T790M and T790 Wild-Type Resistant Subclones Drive Mixed Response to ThirdGeneration Epidermal Growth Factor Receptor Inhibitors in Lung Cancer. JCO Precis Oncol. 2018. doi:10.1200/po.17.00263.

52. Mendez MG, Kojima S-I, Goldman RD. Vimentin induces changes in cell shape, motility, and adhesion during the epithelial to mesenchymal transition. FASEB J Off Publ Fed Am Soc Exp Biol. 2010;24:1838-51.

53. Mohebi M, et al. Expression analysis of vimentin and the related IncRNA network in breast cancer. Exp Mol Pathol. 2020;115:104439.

54. Klinge CM, Piell KM, Tooley CS, Rouchka EC. HNRNPA2/B1 is upregulated in endocrine-resistant LCC9 breast cancer cells and alters the miRNA transcriptome when overexpressed in MCF-7 cells. Sci Rep. 2019. doi:10.1038/s41598-019-45636-8.

55. Dong $\mathrm{H}$, et al. Long non-coding RNA SNHG14 induces trastuzumab resistance of breast cancer via regulating PABPC1 expression through H3K27 acetylation. J Cell Mol Med. 2018. doi:10.1111/jcmm.13758.

56. Zhu J, et al. Chaperone Hsp47 Drives Malignant Growth and Invasion by Modulating an ECM Gene Network. Cancer Res. 2015;75:1580-91.

57. Bonomi S, et al. HnRNP A1 controls a splicing regulatory circuit promoting mesenchymal-to-epithelial transition. Nucleic Acids Res. 2013. doi:10.1093/nar/gkt579. 
58. Dingerdissen HM, et al. BioMuta and BioXpress: Mutation and expression knowledgebases for cancer biomarker discovery. Nucleic Acids Res. 2018. doi:10.1093/nar/gkx907.

59. Zhang X, Su L, Sun K. Expression status and prognostic value of the perilipin family of genes in breast cancer. Am. J. Transl. Res. (2021).

60. Yang H, Antoine DJ, Andersson U, Tracey KJ. The many faces of HMGB1: molecular structure-functional activity in inflammation, apoptosis, and chemotaxis. J Leukoc Biol. 2013;93:865-73.

61. Sun S, et al. High mobility group box-1 and its clinical value in breast cancer. Onco Targets Ther. 2015;8:413-9.

62. Sohun $\mathrm{M}$, Shen $\mathrm{H}$. The implication and potential applications of high-mobility group box 1 protein in breast cancer. Ann Transl Med. 2016;4:217.

63. Xu J, Wu D, Wang S, Wang Z. MAT2B expression correlates with poor prognosis in triple-negative breast cancer. Cancer Manag Res. 2019. doi:10.2147/CMAR.S200716.

64. Vasan N, Baselga J, Hyman DM. A view on drug resistance in cancer. Nature. 2019;575:299-309.

65. Housman G, et al. Drug resistance in cancer: An overview. Cancers. 2014;6:1769-92.

66. Schrörs B, et al. Multi-Omics Characterization of the 4T1 Murine Mammary Gland Tumor Model. Front Oncol. 2020. doi:10.3389/fonc. 2020.01195 .

67. Hum NR, et al. Comparative molecular analysis of cancer behavior cultured in vitro, in vivo, and ex vivo. Cancers (Basel). 2020. doi:10.3390/cancers12030690.

68. Guo ML, et al. Proteomic analysis of the effects of cell culture density on the metastasis of breast cancer cells. Cell Biochem Funct. 2019. doi:10.1002/cbf.3377.

69. Liu YR, et al. Comprehensive transcriptome analysis identifies novel molecular subtypes and subtype-specific RNAs of triple-negative breast cancer. Breast Cancer Res. 2016. doi:10.1186/s13058-016-0690-8.

70. Eden E, Navon R, Steinfeld I, Lipson D, Yakhini Z. GOrilla: A tool for discovery and visualization of enriched Go terms in ranked gene lists. BMC Bioinformatics 10, (2009).

71. Enerly E, et al. miRNA-mRNA integrated analysis reveals roles for mirnas in primary breast tumors. PLoS One 6, (2011).

72. Eden E, Lipson D, Yogev S, Yakhini Z. Discovering Motifs in Ranked Lists of DNA Sequences. PLoS Comput Biol. 2007;3:e39.

73. Polikovsky $\mathrm{M}$, et al. In silico food allergenic risk evaluation of proteins extracted from macroalgae Ulva sp. with pulsed electric fields. Food Chem. 276, (2019).

\section{Figures}



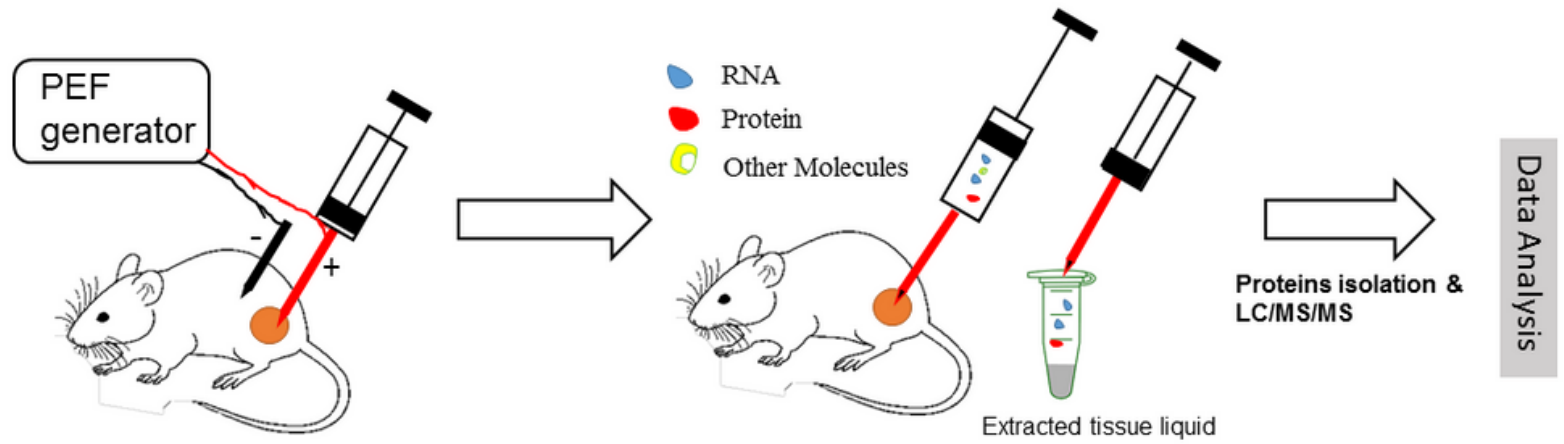

b
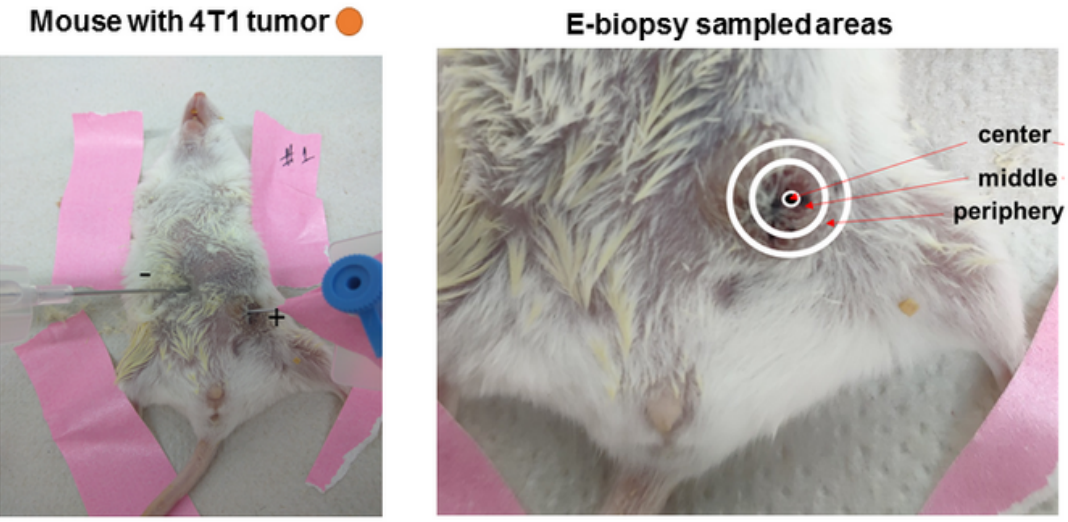

Figure 1

a. Schematic depiction of molecular harvesting in vivo with e-biopsy. b. Digital image of the e-biopsy procedure. The left image shows the insertion of the needle into areas of the tumor and the normal breast. The right image shows the sampled locations: center, middle, and periphery. Two samples were taken from each location.
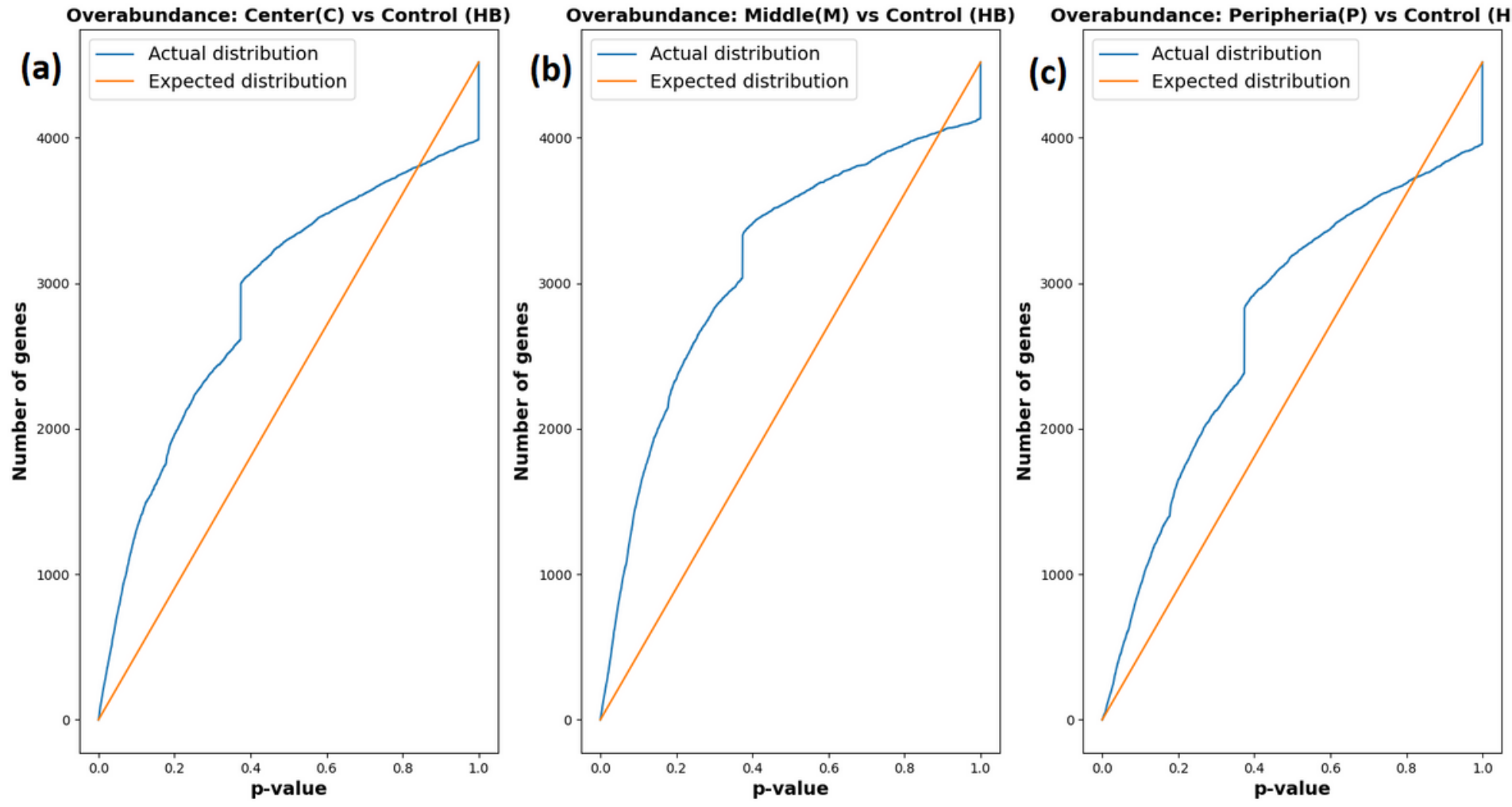

Figure 2 


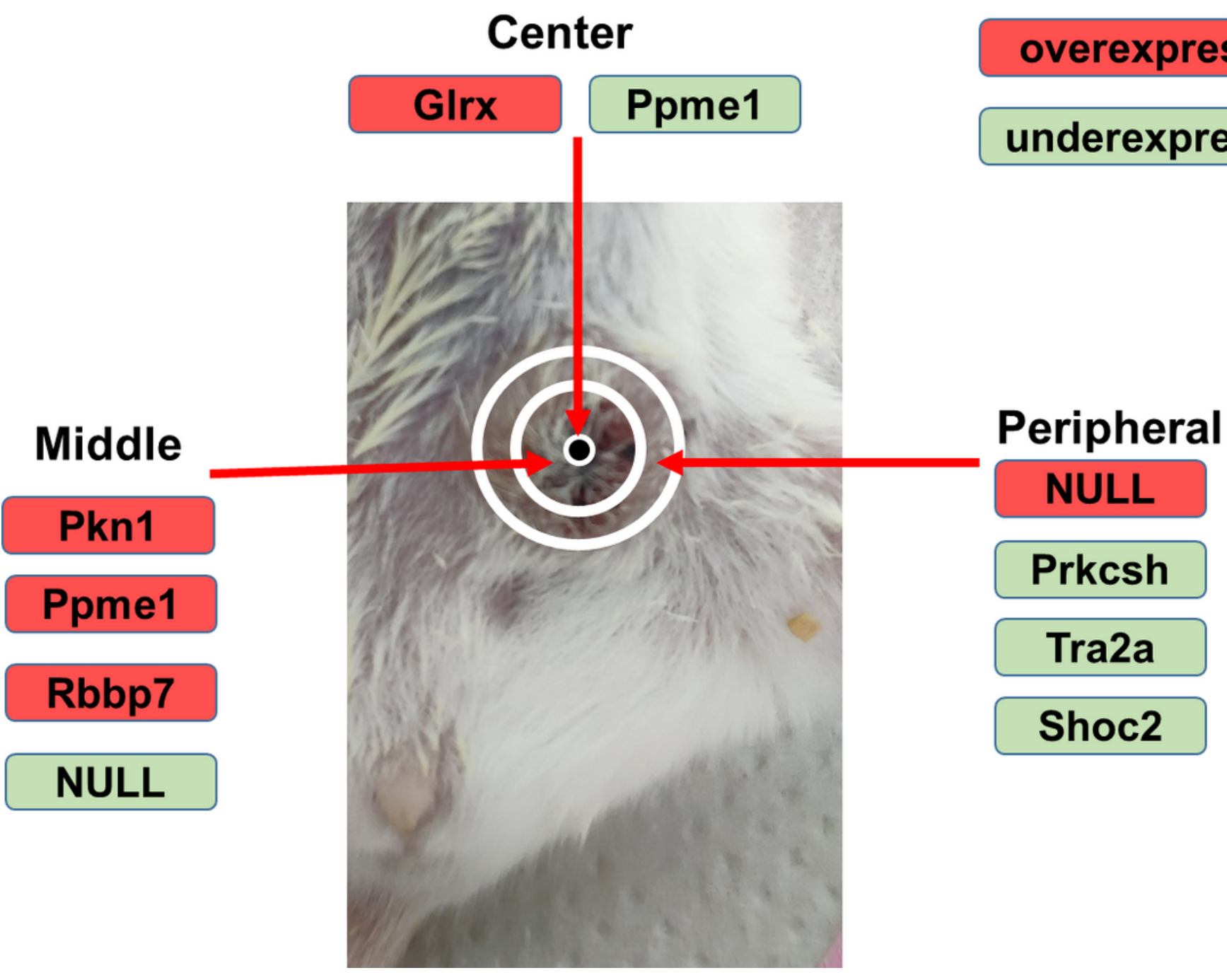

Figure 3

Molecular cartography of a 4T1 murine tumor, showing the potential tumor biomarker genes (p-value $<0.05)$ that are differentially expressed in a single one of the three spatial zones simultaneously compared ( $p$-value < 0.05 ) to two others: center, middle, and periphery (Fig. 1). Overexpression direction (red) and underexpression direction (green) are indicated, NULL shows that no genes were funds under specific classification. 
Overabundance plot: Center(C) vs Middle(M) Overabundance plot: Center(C) vs Peripheria(P)Overabundance plot: Middle(M) vs Peripheria(P)
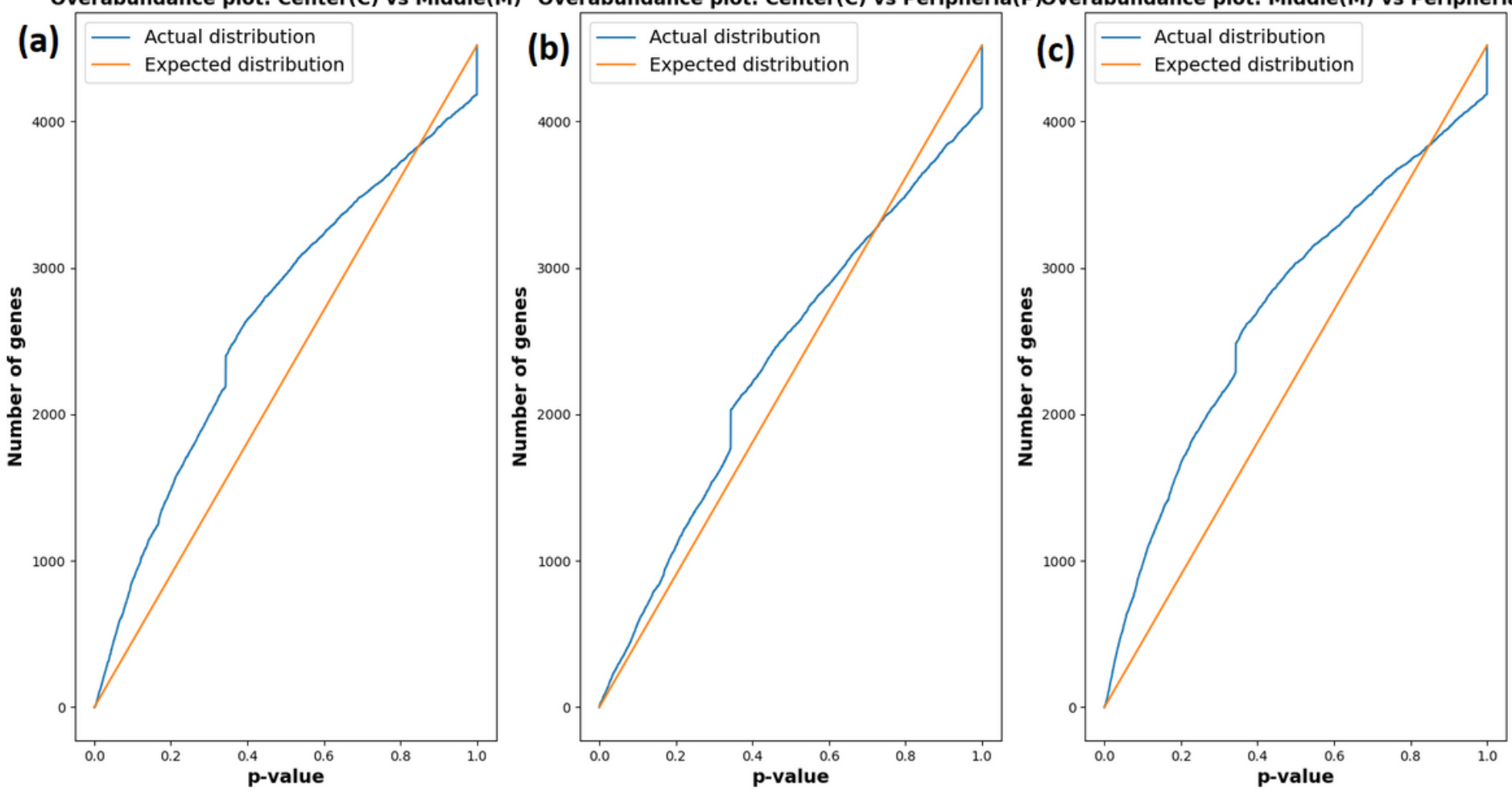

Figure 4

Overabundance plots comparing (Methods) the distribution of the protein differential expression scores between 4T1 tumor locations. Total 5 mice and 4,519 proteins extracted by e-biopsy in 2 location replicas per sample were analyzed. (a) 4T1 center vs 4T1 periphery; (b) 4T1 center vs $4 \mathrm{~T} 1$ middle; (c) $4 \mathrm{~T} 1$ middle vs $4 \mathrm{~T} 1$ periphery.

\section{Supplementary Files}

This is a list of supplementary files associated with this preprint. Click to download.

- Supplementaryinformation.docx

- Tables2correlations.xlsx

- TableS3Uniquelycapturedproteins.xlsx

- TableS4IntratumorMarkers.xlsx

- TableS5All4T1Data.xlsx 